\title{
ANALYSIS OF GARTANIN IN EXTRACT OF MANGOSTEEN PERICARP FRUIT(Garcinia mangostana L.)USING SPECTROPHOTOMETRIC FOURIER TRANSFORM INFRARED(FTIR) METHOD
}

\author{
Muchtaridi Muchtaridi1", ${ }^{1,}$ Rimadani Pratiwi ${ }^{1}$, Gemini Alam² \\ and Abdul Rohman ${ }^{3}$ \\ ${ }^{1}$ Department of Pharmaceutical Analysis and Medicinal Chemistry, Faculty of Pharmacy, \\ UniversitasPadjadjaran, Jatinangor-Sumedang, 45363, Indonesia \\ ${ }^{2}$ Faculty of Pharmacy, Universitas Hasanudin, Makasar, 90245 \\ ${ }^{3}$ Faculty of Pharmacy, Universitas Gadjah Mada, Yogyakarta, 55281 \\ *E-mail:muchtaridi@unpad.ac.id
}

\begin{abstract}
Gartanin is one of derivated xanthone compound in the pericarp of the mangosteen fruit. Gartanin has several pharmacological activities such as antifungal, antioxidant, anticancer bladder, and anticancer lung. The aims of this research are to analyze gartanin in the extract of mangosteen pericarp that combines with partial least squares multivariate calibration to determine the correlation between the concentration of gartanin in the extract of mangosteen pericarp that analyzes by HPLC and by FTIR spectroscopy. The wavenumbers region of $4000-650 \mathrm{~cm}^{-1}$ was selected for prediction of gartanin in the extracts. The correlation between actual values of gartanin determined by HPLC and FTIR predicted values using FTIR spectroscopy combined with PLS. The results showR ${ }^{2}$ values for each region are 0.988 and 0.981 for Subang and Tasikmalaya, respectively and for cross-validation values $\mathrm{R}^{2}=$ 0.838 , PRESS $=0.0068898$, and RMSEC $=0.0003192$ for Subang and $\mathrm{R}^{2}=0.969$, PRESS $=0.0007422$, dan RMSEC $=0.0002151$ for Tasikmalaya. The high value of $\mathrm{R}^{2}$ and low value of RMSEC indicated the high accuracy and precision of FTIR spectroscopy for quantification of gartanin in the extracts. These results indicated that FTIR spectroscopy combined with PLS is an alternative technique for determination of gartanin in the extract of mangosteen pericarp (Garcinia mangostana L.).
\end{abstract}

Keywords: Mangosteen Pericarp, Gartanin, HPLC, FTIR, Partial Least Square

(C) RASĀYAN. All rights reserved

\section{INTRODUCTION}

Garcinia mangostana L. (mangosteen), the Queen of tropical fruits, is a tropical evergreen fruit tree that the most treasured part of the plant and the remarkably pleasant flavor. ${ }^{1,2}$ Mangosteen has a dark to redpurple fruit with the edible fruit aril is white and juicy. The pericarp of mangosteen is usually used as a traditional medicine in Thai for the treatment of wound, diarrhea, and skin infection. ${ }^{3-6}$ The mayor bioactive secondary metabolites compound from mangosteen are xanthone derivative.$^{7-9}$ Gartanin is one of xanthone derivative in the pericarp of the mangosteen fruit. It has multiple targeting agents as a chemopreventive for human urinary bladder cancer. ${ }^{10}$

Some of the analytical methods for analysis xanthone derivative have been reported using HighPerformance Liquid Chromatography (HPLC) and Liquid Chromatography-Mass Spectrometer (LCMS). ${ }^{11-14}$ Though these are a reliable method, they required an expensive cost for routine analysis. Recently, Fourier Transform Infrared (FTIR) spectrometer has been widely used for herbal medicines analysis $^{15}$ and quantitative analysis ${ }^{16}$. FTIR can be used for the identification and quantification of a mixture compound. Qualitative analysis is observed by looking at the shape of the spectrum and the specific peaks that show types of functional groups possessed by these compounds. While the quantitative

Rasayan J. Chem., 12(2), 874-879(2019)

http://dx.doi.org/10.31788/RJC.2019.1225216

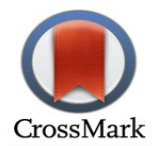


analysis can be determined by observing the spectrum based on the standard compound at various concentration.

In this work, gartanin from the extract of mangosteen pericarp was determined by FTIR compared to HPLC as a reference method. The multivariate calibration of Partial Least Square (PLS) method was used to find the correlation between FTIR and HPLC data.

\section{EXPERIMENTAL}

\section{Materials}

All chemicals used were of analytical grade and used without further purification. Gartanin standard was purchased from Chengdu Biopurified, Cina. $\mathrm{KBr}$, methanol HPLC grade, phosphoric acid, acetonitrile HPLC grade were obtained from Merck. FTIR spectra were performed on FTIR P-21 Shimadzu. HPLC

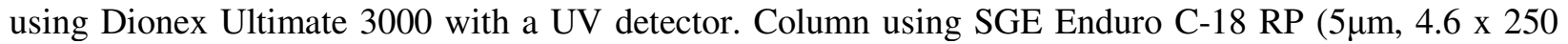
$\mathrm{mm}$ ). The mangosteen pericarp was obtained from Subang and Tasikmalaya, West Java, Indonesia. This mangosteen pericarp was extracted by maceration using methanol-water for 72 hours. The extract was evaporated at $60^{\circ} \mathrm{C}$ to constant weight then dried in an oven at $70^{\circ} \mathrm{C}$.

\section{Methods}

\section{FTIR analysis}

Each of mangosteen pericarp extract (from Subang and Tasikmalaya) was divided into 7 variation concentration (4-10\%). Each of sample is made pellet with $\mathrm{KBr}$ then measured by FTIR.

\section{HPLC analysis}

Mangosteen pericarp extract $(5 \mathrm{mg})$ was dissolved in methanol and sonicated. The solution was filtered using millipore filter paper $0.45 \mu \mathrm{m}$. Then $10 \mu \mathrm{L}$ solution was injected to HPLC with mobile phase acetonitrile:phosphoric acid $0.1 \%$ in aquabidestilata (95:5), flow rate $1 \mathrm{~mL} /$ minute, and UV detector in $375 \mathrm{~nm}$.

\section{Statistical analysis}

The multivariate calibration of PLS for the correlation between the actual value of gartanin as determined with HPLC and FTIR predicted value was performed using Horizon software included in FTIR spectrophotometer. The leave-one-out cross-validation procedure was used to verify the calibration model. The values of Root Mean Square Error of Calibration (RMSEC) and coefficient of determination $\left(\mathrm{R}^{2}\right)$ were used as the validity criteria for the calibration model. The predictive ability of the PLS calibration model was further used to calculate the validation or prediction samples.

\section{FTIR Analysis}

\section{RESULTS AND DISCUSSION}

The FTIR analysis spectra of seven variations of mangosteen pericarp extract from Subang and Tasikmalaya are shown in Fig.-1 and Fig.-2, respectively. In this study, the analysis gartanin compounds using FTIR spectrophotometry was performed at wave number $650-4000 \mathrm{~cm}^{-1}$ and scanned in the absorbance form. The absorbance was taken from a lot of wave number and used to predict the content of gartanin in the extract compared to HPLC data. The result of FTIR analysis can confirm that the sample contains gartanin compound. The $-\mathrm{OH}$ stretching in Table-1 related to the hydroxyl group of gartanin. The strong intensity around $1600 \mathrm{~cm}^{-1}$ shows the functional group of $\mathrm{C}=\mathrm{O}$ in gartanin. $\mathrm{C}=\mathrm{C}$ and $\mathrm{C}-\mathrm{H}$ aromatic also was predicted that the sample contains gartanin. Fig.-1 and Fig.-2 showed the absorbance of seven variation concentration of extract increase as the concentration of extract increased.

The analysis was continued using High-Performance Liquid Chromatography (HPLC) to ensure the amount of gartanin in sample extract. Quantification of gartanin in the extract was determined by using a calibration curve of gartanin standard. The linear range gartanin standard of 5, 10, 20, 40, and $80 \mathrm{ppm}$ was $\mathrm{y}=0.0037 \mathrm{x}+0.0011$ with an $\mathrm{R}^{2} 0.9991$. The seven variation of gartanin in extract mangosteen pericarp was shown in Table-2 and Table-3. The results showed that the concentration of gartanin in extract mangosteen pericarp from Subang around 2-4 ppm, while from Tasikmalaya around $2-7 \mathrm{ppm}$. 
RASĀYAN J. Chem.

Vol. 12 | No. 2 |874 - 879| April - June | 2019

Table 1: The Predicted Functional Groups that Responsible for Gartanin Analysis

\begin{tabular}{c|c}
\hline Wavelength Number $\left(\mathrm{cm}^{-1}\right)$ & Functional Groups \\
\hline 3399,6 & O-H stretching vibration \\
\hline 2929,92 & C-H stretching aliphatic \\
\hline 1456,28 & $\mathrm{C}=\mathrm{C}$ stretching aromatic \\
\hline 1617,34 & $\mathrm{C}=\mathrm{O}$ stretching vibration \\
\hline 1185,28 & O-H bending vibration \\
\hline 1071,48 & C-O alcohol \\
\hline 637,48 & C-H aromatic \\
\hline
\end{tabular}

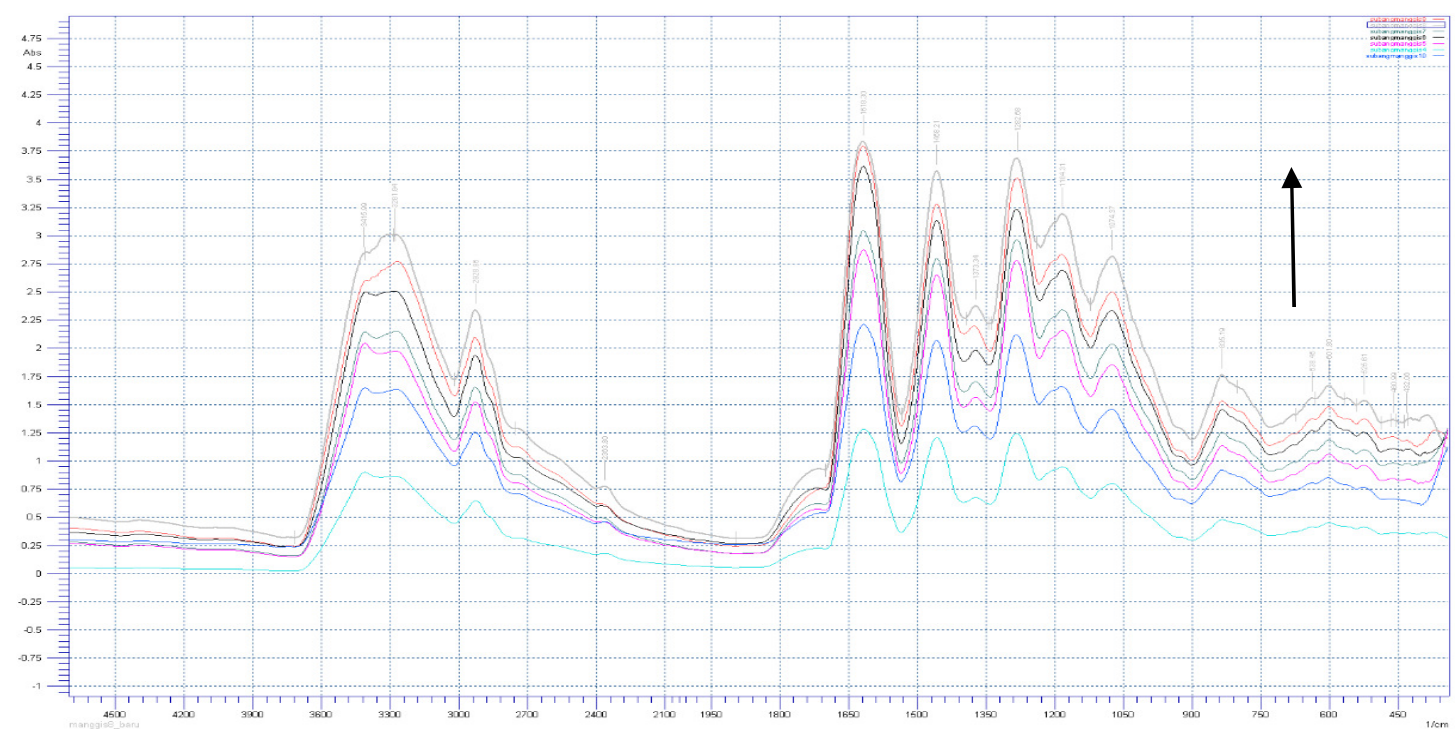

Fig.-1: The FTIR Spectra of Mangosteen Pericarp Extract from Subang in Variation Concentration

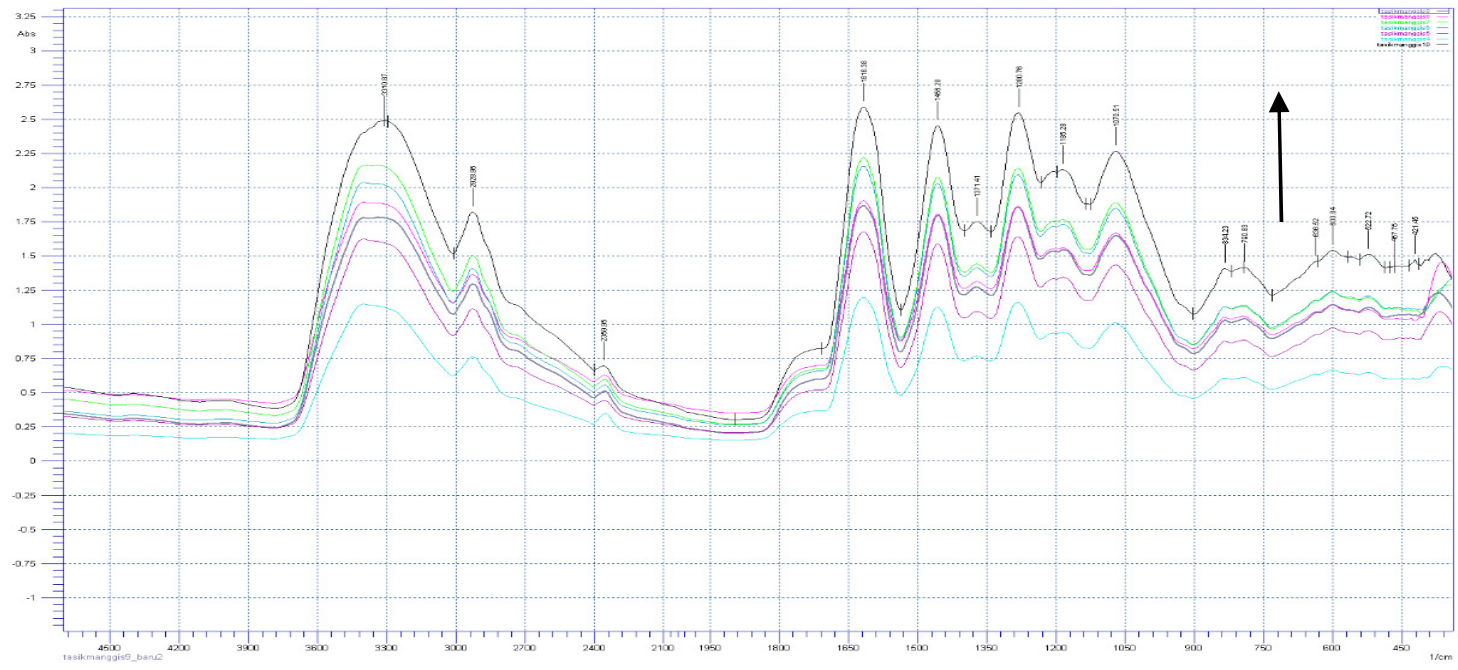

Fig.-2: The FTIR Spectra of Mangosteen Pericarp Extract from Tasikmalaya in Variation Concentration

The data was obtained from FTIR and HPLC analysis was continued analysis using the multivariate calibration of Partial Least Square (PLS) method, as one of the chemometric analysis, to find the correlation between FTIR and HPLC data.PLS multivariate calibration analyzes multi components that calibrate predictor variables (absorbance in wave numbers series) with high correlation with dependent variables (gartanin concentration). In this data processing, PLS helps to calibrate and quantify gartanin 
compounds in mangosteen peel extracts (Garciniamangostana L.), with the intensity (absorbance) of gartanine functional groups on specific waves as predictor variables and gartanin concentrations as dependent variables.

Table-2: The Measurement of Gartanin in Extract Mangosteen Pericarp from Subang

\begin{tabular}{c|c|c|c}
\hline Sample & $\begin{array}{c}\text { Average of } \\
\text { Area } \\
\text { (AUC) }\end{array}$ & $\begin{array}{c}\text { Average of } \\
\text { Concentration } \\
(\mathrm{ppm})\end{array}$ & $\begin{array}{c}\text { The concentration of gartanin } \\
(\mathrm{wt} / \mathrm{wt} \pm \mathrm{SD} \%)\end{array}$ \\
\hline 1 & 0.016 & 4.027 & $10,140 \pm 0,08$ \\
\hline 2 & 0.012 & 2.46 & $5.890 \pm 0,05$ \\
\hline 3 & 0.008 & 1.65 & $3.110 \pm 0,12$ \\
\hline 4 & 0.020 & 5.108 & $7.295 \pm 0,21$ \\
\hline 5 & 0.012 & 2.946 & $9.205 \pm 0,04$ \\
\hline 6 & 0.015 & 3.757 & $10.435 \pm 0,07$ \\
\hline 7 & 0.020 & 5.108 & $12.770 \pm 0,08$ \\
\hline
\end{tabular}

Table-3: The Measurement of Gartanin in Extract Mangosteen Pericarp from Subang

\begin{tabular}{c|c|c|c}
\hline Sample & $\begin{array}{c}\text { Average of } \\
\text { Area } \\
\text { (AUC) }\end{array}$ & $\begin{array}{c}\text { Average of } \\
\text { Concentration } \\
(\mathrm{ppm})\end{array}$ & The concentration of gartanin (wt/wt \pm SD \%) \\
\hline 1 & 0.012 & 2.946 & $5.895 \pm 0,22$ \\
\hline 2 & 0.012 & 2.946 & $5.895 \pm 0,14$ \\
\hline 3 & 0.018 & 4.568 & $7.615 \pm 0,35$ \\
\hline 4 & 0.027 & 7.000 & $10.000 \pm 0,11$ \\
\hline 5 & 0.013 & 3.216 & $10.050 \pm 0,19$ \\
\hline 6 & 0.010 & 2.405 & $6.680 \pm 0,09$ \\
\hline 7 & 0.018 & 4.568 & $11.420 \pm 0,07$ \\
\hline
\end{tabular}

Data processing using PLS aims to see the suitability of gartanin content obtained by FTIR spectrophotometric method with the level of gartanin obtained by HPLC method. The analysis was performed on the chosen wave number that could produce the highest correlation between the variables, so not all data obtained from the research results are processed in the PLS processing. The gartanin content obtained from the test results using HPLC was used as actual data (actual value). Critical parameters in the analysis with PLS are a number of factors analyzed ${ }^{17}$. A number of factors are selected as a parameters are the lowest value PRESS (Predicted Residual Error of Sum Square) and the highest $\mathrm{R}^{2}$ value. In addition, other data was obtained from PLS is the value of the difference between the actual value and the predicted value. This difference is expressed as a residual value. The higher the residual value (close to 0 ) describes the strength of the correlation between the two variables ${ }^{18}$. The reliability of a calibration model appraised the value of $\mathrm{R}^{2}$ (coefficient of determination) linking between two variables, the actual content (actual response) versus contents counted (calculated response).

In this research, the value of the coefficient of determination $\left(\mathrm{R}^{2}\right)$ for samples of skin extracts of mangosteen (Garcinia mangostana $\mathrm{L}$ ) from Subang is 0.995 with a regression equation $\mathrm{y}=0.9950 \mathrm{x}+$ 0.000846 and samples from Tasikmalayais 0.991 with a regression equation $y=0.9906 x+0.001566$, as shown in Fig.-3 and Fig.-4, respectively. There are no specific standards for the achievement of the $\mathrm{R}^{2}$ value because the value is only described as appropriateness or suitability of a method tested by the comparison method. The $\mathrm{R}^{2}>0.99$ indicates that the calibration models were used to predict gartanin content in the extract is accurate. Determination coefficient value from this study indicated that FTIR spectrophotometry has equal to $98.8 \%$ for Subang area and $98.1 \%$ for Tasikmalaya area. The high determinant value showed that the modeling of gartanin analysis with FTIR spectrophotometry was appropriate and able to quantify gartanin in mangosteen peel extract (Garcinia mangostana L.) according to the analysis using HPLC method.

Model calibration was further performed cross-validation (cross-validation) using a leave-one-out technique. Using this technique, a sample calibration eliminated one by one and modeled with calibration samples remaining. Once again the value of $\mathrm{R}^{2}$ is used to look at the accuracy of the model pattern of the 
relationship between the content of the actual gartanin with predictable calibration samples were subjected to cross-validation. This cross-validation generate value $\mathrm{R}^{2}=0.838$ for the area of Subang area and $\mathrm{R}^{2}=0.969$ for Tasikmalaya area. The closer to zero a value PRESS, then power the better predictive models ${ }^{18}$.

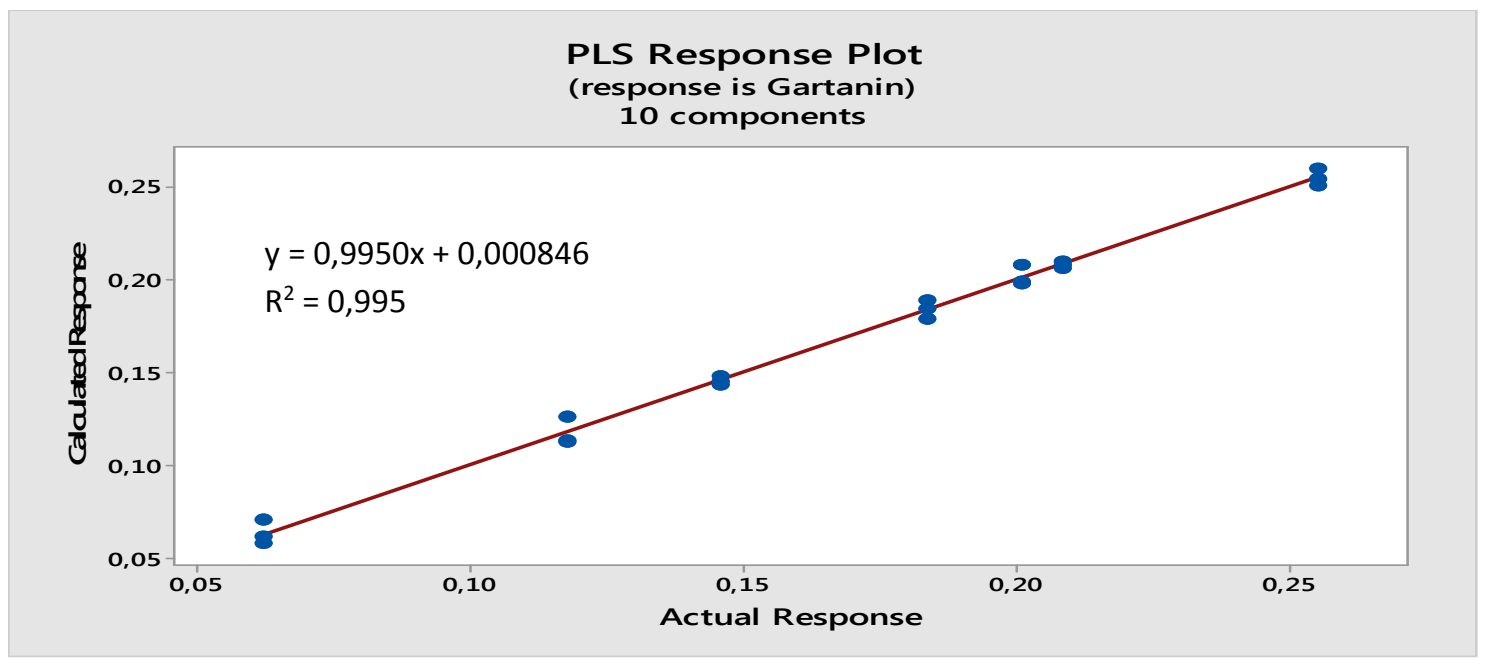

Fig.-3: The Correlation between Actual Values of Gartanin in the Extract of Garcinia mangostana L. from Subang Determined by HPLC and Predicted Values using FTIR Spectroscopy Combined with PLS

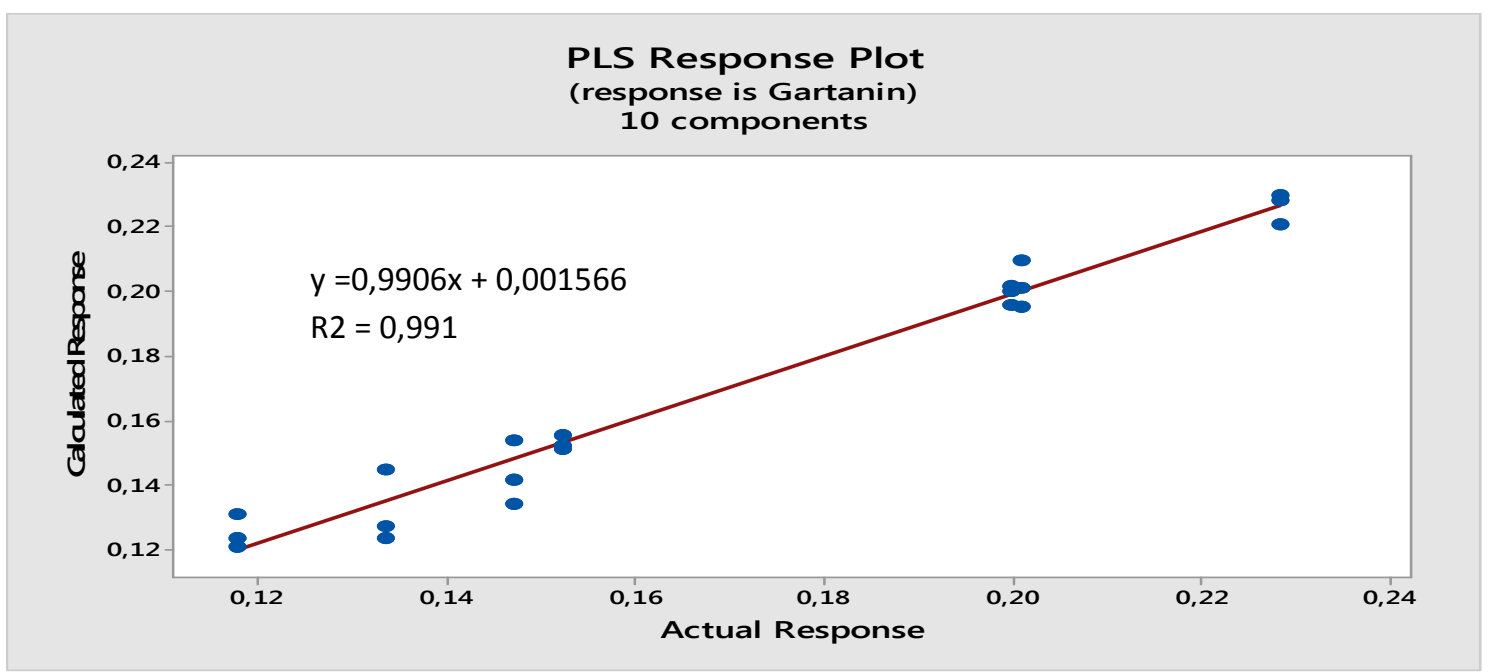

Fig.-4: The Correlation between Actual Values of Gartanin in the Extract of Garcinia mangostana L. from Tasikmalaya Determined by HPLC and Predicted Values using FTIR Spectroscopy Combined with PLS

\section{CONCLUSION}

The spectrophotometry Fourier Transform Infrared (FTIR) method can be used to the quantification of gartanin in the extract of mangosteen pericarp fruit by chemometric analysis. This data was compared with HPLC data to find the correlation of both methods using the multivariate calibration of Partial Least Square (PLS) method. The result show $\mathrm{R}^{2}$ values are 0.988 and 0.981 with $\mathrm{RMSEC}=0.0003192$ and RMSEC $=0.0002151$ for Subang and Tasikmalaya, respectively. The high value of $R^{2}$ and low value of RMSEC indicated the high accuracy and precision of FTIR spectroscopy for quantification of gartanin in the extracts.

\section{ACKNOWLEDGMENT}

We would like to thanks to Noviyanti Tambunan who helps some part of this project. This study was supported by The Directorate General of Higher Education of The Ministry of Research and Technology of Indonesia through Indonesia Collaboration Research 2019 grant. 
RASĀYAN J. Chem.

Vol. 12 | No. 2 |874 - 879| April - June | 2019

\section{REFERENCES}

1. B. Ovalle-Magallanes, D. Eugenio-Pérez, Pedraza-Chaverri, J. Food and Chemical Toxicology, 109 (1), 102 (2017), DOI: $10.1016 /$ j.fct.2017.08.021

2. C.M. Ramage, L. Sando, C.P. Peace, B.J. Carroll, and R.A. Drew RA, Euphytica, 136(1) , 1(2004)

3. W. Mahabusarakam andP. Wiriyachitra,J Nat Prod, 50, 3,(1987), DOI: 10.1021/np50051a021

4. P. Moongkarndi, N. Kosem, S. Kaslungka, O. Luanratana, N. Pongpan, and N. Neungton, $J$ Ethnopharmacol, 90(1), 161 (2004), DOI: 10.1016/j.jep.2003.09.048

5. F.W. Martin. Durian and mangosteen. In Tropical and Subtropical Fruits: Composition, Properties and Uses. Westport, CT AVI Publishing, pp. 407-414 (1980)

6. J. Pedraza-Chaverri, N. Cárdenas-Rodríguez, M. Orozco-Ibarra, and J.M. Pérez-Rojas, Food and Chemical Toxicology, 46(1), 3227 (2008), DOI: 10.1016/j.fct.2008.07.024

7. H.A. Jung, B.N. Su, W.J. Keller, R.G. Mehta, and A.D. Kinghorn, J Agric Food Chem, 54 (6), 2077 (2006), DOI: $10.1021 / \mathrm{jf052649}$

8. V. Peres, T.J. Nagem, andF.F. De Oliveira, Phytochemistry, 55, 683 (2000), DOI: 10.1016/S00319422(00)00303-4

9. S. Suksamrarn, N. Suwannapoch, P. Ratananukul, N. Aroonlerk, A. Suksamrarn, J Nat Prod, 65, 5 (2002), DOI: $10.1021 / \mathrm{np} 010566 \mathrm{~g}$

10. Z. Liu, M. Antalek, L. Nguyen, X. Li, X. Tian, A. Le, and X. Zi, Nutrition and Cancer, 65(suppl 1), 68 (2013), DOI: 10.1080/01635581.2013.785011

11. E.B. Walker, J Sep Sci, 30(9), 1229 (2007), DOI:10.1002/jssc.200700024

12. S. Kongkiatpaiboon, B. Vongsak, S. Machana, T. Weerakul, and C. Pattarapanich, J King Saud Univ Sci, 28(20), 131 (2016), DOI: 10.1016/j.jksus.2015.06.007

13. Muchtaridi, M. Prasetio, N.M. Saptarini, and F.A. Saputri, Rasayan J. Chem, 11(3), 973 (2018), DOI: $10.31788 /$ RJC.2018.1132098

14. S. Yodhnu, A. Sirikatitham, and C. Wattanapiromsakul, J Chromatogr Sci, 47(3), 185(2009), DOI: 10.1093/chromsci/47.3.185

15. A. Rohman, A. Nugroho, E. Lukitaningsih, and Sudjadi, Applied Spectroscopy Reviews, 49(8), 603 (2014), DOI: 10.1080/05704928.2014.882347

16. D.M. MacKie, J.P. Jahnke, M.S. Benyamin, and J.J Sumner, MethodsX, 3, 128 (2016), DOI:10.1016/j.mex.2016.02.002

17. K. Tanaka, Y. Kuba, T. Sasaki, F. Hiwatashi, and K. Komatsu,J Agric Food Chem, 56(19), 87 (2008), DOI: 10.1021/jf801338e

18. A. Rácz, D. Bajusz, K. Héberger, In Applied Chemoinformatics, ed. T. Engel, J. Gasteiger, Germany, Wiley - VCH Verlag GmbH \& Co. KgaA, 1(9), pp. 471 (2018), DOI: 10.1002/9783527806539.ch9

[RJC-5216/2019] 